\title{
Clinical usefulness of temporal artery biopsy
}

\author{
J VILASECA ${ }^{1}$ A GONZÁLEZ, ${ }^{1}$ M C CID ${ }^{3}$ J LOPEZ-VIVANCOS, ${ }^{1}$ AND \\ A ORTEG ${ }^{2}$
}

From the Departments of ${ }^{1}$ Medicine and ${ }^{2}$ Pathology, Hospital Vall d'Hebron, Universidast Autonoma, and the ${ }^{3}$ Hospital Clinic, Barcelona, Spain

SUMmaRY To assess the diagnostic usefulness of temporal artery biopsy in temporal arterit (TA) and establish clinical features capable of predicting its positivity we have retrospective studied the biopsy specimens and the clinical features of 103 patients who had undergone temporal artery biopsy. Temporal artery biopsy reached a positive predictive value of $90 \cdot 2 \%$ with respect to the final diagnosis based on the criteria proposed by Ellis and Ralston and the clinicå course. The simultaneous presence of recent onset headache, jaw claudication, and abnormalg ties of the temporal arteries on physical examination had a specificity of $94.8 \%$ with respect to the histological diagnosis and of $100 \%$ with respect to final diagnosis. The presence of any of thes clinical features, though of little specificity $(34 \cdot 4 \%)$, had a sensitivity of $100 \%$ with respect to histological diagnosis, selecting a group of patients in whom temporal artery biopsy has more discriminative value.

Key words: temporal arteritis.

Temporal arteritis (TA) is a systemic vasculitis common in elderly people which affects large and medium sized vessels, in particular the carotid branches. This fact conditions its classic clinical manifestations and makes its histological diagnosis easy. Since the original description by Horton $e t$ al, ${ }^{1}$ diagnosis is achieved by biopsy of the superficial temporal artery. The segmental nature of the lesions $^{2}$ can give rise to false negative biopsies. Moreover, the numerous descriptions of atypical presenting forms ${ }^{3-5}$ have increased the index of suspicion and, in the same way, the number of negative results. ${ }^{6}$ Because of this, there remains controversy about the diagnostic usefulness of temporal artery biopsy. ${ }^{7-11}$

We have conducted the present study to assess the diagnostic usefulness of temporal artery biopsy and find clinical features that can predict its positivity.

\section{Patients and methods}

The names of all patients who underwent temporal artery biopsy between 1970 and 1984 were obtained through the archives of our pathology department.

Accepted for publication 30 September 1986.

Correspondence to Dr A González Fernández, Avda. Hospital Militar 158-A, 4,2, 08023-Barcelona, Spain.
The medical records were reviewed for informatio on clinical manifestations, laboratory findings, ar clinical course during a median follow up of 54 months.

Biopsy specimens were examined by one of is (AO) without knowledge of the clinical and origingl histological diagnosis. Histological diagnosis of Ts was established by demonstration of lesions defineed as classical giant cell arteritis, atypical giant ce्bl

Table 1 Temporal arteritis: diagnosis criteria

1 Age greater than 55

2 Positive response within $\mathbf{4 8}$ hours to corticosteroid therappo

3 Length of history greater than two weeks

4 Positive temporal artery biopsy

5 Proximal, symmetrical girdle or upper arm muscle pain, $\sigma$ stiffness, or tenderness

6 Jaw claudication

7 Clinical abnormality of a temporal artery (tenderness, thickening, redness)

8 Systemic symptoms or signs (malaise, anorexia, weight loss anaemia, pyrexia)

9 Recent onset headache

10 Visual disturbance (loss, diplopia, blurring)

Criteria 1-3 plus any three of criteria 5-10 required for clinie diagnosis.

From Ellis and Ralston. ${ }^{12}$ 
arteritis, or healed giant cell arteritis according to Allsop and Gallagher. ${ }^{7}$

In those patients with a negative biopsy we used the criteria proposed by Ellis and Ralston ${ }^{12}$ to establish the clinical diagnosis of TA (Table 1).

Student's $t$ test was used for the analysis of quantitative variables. A $\chi^{2}$ test of significance with Yates's correction was used for all $2 \times 2$ tables.

\section{Results}

One hundred and three patients underwent temporal artery biopsy between 1970 and 1984. In 45 cases $(43.7 \%)$ biopsy was diagnostic and in 58 $(56.3 \%)$ was negative. Ten out of 58 patients with negative biopsy fulfilled the Ellis and Ralston clinical criteria and were considered to be affected by TA. These patients were followed up for a mean of 40.6 months (range 15-89) with complete remission of corticosteroid therapy and no other potential cause for their complaints emerging. The final diagnosis of the other 48 patients is shown in Table 2. In the three patients with no final diagnosis the clinical criteria were not fulfilled, their symptoms were non-specific or disappeared in few months without corticosteroid therapy.

The fact that the negative artery biopsy specimens were significantly longer $(1.4 \mathrm{~cm}$; range $0.2-6 \mathrm{~cm})$ than the positive ones $(1.1 \mathrm{~cm}$; range $0.1-5 \mathrm{~cm}$ $(p<0.005))$ demonstrates that biopsy specimens were adequate and had no influence on the results.

Clinical findings are shown in Table 3. Age and sex distributions of the groups with positive (group A) and negative (group B) biopsy were similar (group A: $42 \%$ men; median age 69.8 years (range

Table 2 Negative temporal artery biopsy: final diagnosis $(n=58)$

\begin{tabular}{|c|c|c|}
\hline \multicolumn{2}{|l|}{ Diagnosis } & \multirow{2}{*}{$\begin{array}{l}\text { Number } \\
15\end{array}$} \\
\hline Polymyalgia rheumatica & & \\
\hline Temporal arteritis & & 10 \\
\hline Infections & & 3 \\
\hline Pneumonia & & \\
\hline Urinary tract 1 & & \\
\hline Atherosclerotic vascular disease & & 6 \\
\hline Conective tissue disease & & 9 \\
\hline Rheumatoid arthritis & 2 & \\
\hline Systemic lupus erythematosus & 1 & \\
\hline Reactive arthritis & 1 & \\
\hline Vasculitis & 5 & \\
\hline Miscellaneous & & 2 \\
\hline Chronic hepatitis 1 & & \\
\hline Hypothyroidism 1 & & \\
\hline Malignant disease & & 10 \\
\hline Undiagnosed & & 3 \\
\hline
\end{tabular}

Table 3 Temporal artery biopsy: clinical findings

\begin{tabular}{|c|c|c|}
\hline & $\begin{array}{l}\text { Positive biopsy } \\
(n=45)\end{array}$ & $\begin{array}{l}\text { Negative biopsy } \\
(n=58)\end{array}$ \\
\hline & No (\%) & No $(\%)$ \\
\hline ESR greater than $40 \mathrm{~mm} / \mathrm{h}$ & $45(100)$ & $55(95)$ \\
\hline Myalgias & $24(53)$ & $28(48)$ \\
\hline Arthralgias & $18(40)$ & $22(38)$ \\
\hline Arthritis & $3(7)$ & $7(12)$ \\
\hline Malaise & $32(71)$ & $33(57)$ \\
\hline Anorexia & $32(71)$ & $35(60)$ \\
\hline Weight loss & $27(60)$ & $30(52)$ \\
\hline Anaemia & $28(62)$ & $34(59)$ \\
\hline Fever & $27(60)$ & $26(45)$ \\
\hline Visual disturbance & $15(33)$ & $13(22)$ \\
\hline Headache & $36(80)$ & $27(47)^{*}$ \\
\hline Jaw claudication & $19(42)$ & $7(12)^{*}$ \\
\hline Abnormal temporal artery & $38(84)$ & $21(36)^{*}$ \\
\hline
\end{tabular}

${ }^{*} \mathrm{p}<0.005$ by $\chi^{2}$ test.

$\mathrm{ESR}=$ erythrocyte sedimentation rate.

51-85); group B: $35 \%$ men; median age 68.5 years (range 34-87)). There was great similarity between the two groups in the frequency of muscular and skeletal manifestations (polymyalgia rheumatica, arthritis, arthralgias), of constitutional symptoms (fever, anaemia, weight loss, anorexia, malaise), of increased erythrocyte sedimentation rate (ESR) (group A: median ESR $112.2 \mathrm{~mm} / \mathrm{h}$ (range 47-155); group B: mean ESR $100.8 \mathrm{~mm} / \mathrm{h}$ (range 10-170)), and of visual disturbances, including blindness.

Only jaw claudication, recent onset headache, and abnormalities on physical examination of temporal arteries (tenderness, redness, thickening, diminished or asymmetric pulse) were discriminative. These were significantly more frequent in the patients with positive biopsy $(\mathrm{p}<0 \cdot 005)$. All patients with positive biopsy had at least one of these three findings, whereas 20 patients $(34 \%)$ with negative biopsy had none of them. Eighteen patients with TA had all three features. In 15 of them temporal artery biopsy was positive and the other three were considered to have TA on clinical grounds.

Sensitivity, specificity, and the predictive value of temporal artery biopsy with respect to the final diagnosis were $81 \cdot 8 \%, 100 \%$, and $90.2 \%$ respectively. Despite poor specificity $(34.4 \%)$, the presence of any of the three discriminative clinical features (recent onset headache, jaw claudication, and abnormal temporal arteries) was associated with a $100 \%$ diagnostic sensitivity with respect to the positivity of the biopsy. The simultaneous presence of all three symptoms reached a specificity of $94.8 \%$ with respect to the histological diagnosis and of $100 \%$ with respect to the final diagnosis. 


\section{Discussion}

The diagnosis of temporal arteritis is established by temporal artery biopsy because this is easily obtained and because of the predilection of the illness for this artery. The segmentary character of the lesions, ${ }^{2}$ however, and the fact that they may affect other vascular territories ${ }^{1314}$ means that TA cannot be excluded by a negative result. Thus several methods have been proposed to increase the diagnostic accuracy of temporal biopsy, such as removing a longer segment of artery ${ }^{2}{ }^{15}$ or taking a contralateral biopsy specimen. ${ }^{16}$ Furthermore, the selection of the biopsy site by palpation, ${ }^{24}$ angiography, ${ }^{17}$ or Doppler ${ }^{18}$ and multiple sectioning of the specimen ${ }^{2}$ have been proposed. Despite these manoeuvres, temporal artery biopsy is not diagnostic in all cases and this has led to the establishment of clinical criteria to achieve the diagnosis of TA without histological confirmation. ${ }^{12} 19$ For this reason, and the remote possibility of complications of the procedure, such as stroke, ${ }^{16}$ some authors argue that temporal biopsy is not necessary ${ }^{78}$ as its result does not influence therapeutic decisions. This opinion is not generally accepted because there is a significant percentage of patients that present in an atypical way with predominance of constitutional symptoms $^{3-5}$ or of focal symptoms related to other vascular territories. ${ }^{1314}$ The finding of a positive biopsy is particularly useful in cases in which clinical suspicion is weak. Other authors remark on the usefulness of temporal artery biopsy especially in patients with a poor response to treament, arguing that on rare occasions the temporal artery may be affected by a necrotising vasculitis, such as polyarteritis nodosa, presenting with clinical manifestations similar to those of TA. 920

Hall et al have shown that provided the site and size of the temporal artery biopsy are carefully chosen the result has a predictive value of $94 \%$ with respect to the need for long term treatment. ${ }^{15}$ Although they found a higher frequency of jaw claudication and clinically abnormal temporal arteries in the group of patients with positive biopsy, they did not analyse the predictive value of these or other features on the outcome of the biopsy. In their series the presence of jaw claudication and abnormal temporal arteries had poor sensitivity. Nearly $25 \%$ of the patients with TA presented neither of these features.

The aim of our study was to assess the diagnostic usefulness of temporal artery biopsy in TA and to identify clinical criteria capable of predicting its positivity. Furthermore, we have tried to establish criteria for selection of those patients who would get most advantage from temporal artery biopsy and those in whom it is not necessary. Temporal arte biopsy at our institution achieved a diagnostfe sensitivity of $81.8 \%$, with a positive predictive value of $90 \cdot 2 \%$. In agreement with Hall et al ${ }^{15}$ we conside temporal artery biopsy to be a useful diagnosiffe procedure if correctly performed. In our series the were no significant differences between the grous with positive and negative biopsy with respect to most of the clinical and biological parameter. suggesting that they were appropriately selected for biopsy. Only three features (recent onset headache, jaw claudication, and abnormal temporal arteries ơำ examination) were more frequent in the patien'ts with positive biopsy. The simultaneous presence $8 \mathrm{f}$ these three clinical features is highly specific (all the patients in whom they were present had the finat diagnosis of $\mathrm{TA}, 83 \%$ of them with histological confirmation). Thus in this group of patients the diagnosis of TA could be made without performi a temporal artery biopsy. The presence of any of these three clinical features, though of little specib ficity, had great diagnostic sensitivity $(100 \%$ of the patients with positive histology presented with af least one of them). These, therefore, are the patients in whom temporal artery biopsy would hase the greatest discriminative value. The predictioe accuracy may be due to the careful history obtaing and the detailed examination of the temporot arteries and the rest of the extracraneal arterie $\overrightarrow{\sigma_{\text {, }}}$, evaluating not only inflammatory signs or the absence of pulsation but also minor asymmetries and irregularities. According to our results temporal artery biopsy is unnecessary in those patienes without any of these three discriminative featuress because it will give no additional information. Atypical presentations have been reported, however, and although in some of these clinical examio ation of the temporal arteries was not recorded, ${ }^{21}{ }^{22}$ in others they were normal. ${ }^{23-25}$ We conclude that when, after a careful clinical history and a detailed examination of the extracraneal arteries, none of the above mentioned three clinical features is foun $\$$, temporal artery biopsy should be postponed unitil other investigations are performed. Although this conclusion requires confirmation by prospectife studies, it would be especially useful in the patients with polymyalgia rheumatica, in whom temporal artery biopsy may not be necessary. We think that these patients a correct approach would be to start treatment with low dose corticosteroids. The risk ff clinical or histological vascular lesions appeariog should then be less than $1 \%$, as was found in the follow up of patients with polymyalgia rheumatioa selected by Ayoub et al with less restrictife criteria. ${ }^{26}$ 


\section{References}

1 Horton B T, Magath T B, Brown G E. An undescribed form of arteritis of temporal vessels. Proceeding of the Staff Meetings of the Mayo Clinic. 1932: 7: 700-1.

2 Klein R G, Campbell R J. Hunder C G, Garney J A. Skip lesions in temporal arteritis. Mayo Clin Proc 1976; 51: 504-10.

3 Healey L A, Wilske K R. Presentation of occult giant cell arteritis. Arthritis Rheum 1980; 23: 641-3.

4 Ghose M K, Shensa S, Lerner P L. Arteritis of the aged (giant cell arteritis) and fever of unexplained origin. Am J Med 1976; 60: $429-35$.

5 Healey L A, Wilske K R. Anemia as a presenting manifestation of giant cell arteritis. Arthritis Rheum 1971; 14: 27-31.

6 Huston K A, Hunder G G, Lie J T, Kennedy R H, Elveback L R. Temporal arteritis. A 25-year epidemiologic, clinical and pathologic study. Ann Intern Med 1978; 88: 162-7.

7 Allsop C J, Gallagher P J. Temporal artery biopsy in giant cell arteritis. A reappraisal. Am J Surg Pathol 1981; 5: 317-23.

8 Kirsch U. Temporal artery biopsy. Lancet 1983; i: 646.

9 Giordano M, Valentini G, Vatti M, Tirri G, Picillo U. Temporal artery biopsy. Lancet 1983; i: 646 .

10 Hall S, Hunder G G. Is temporal artery biopsy prudent?. Mayo Clin Proc 1984; 59: 793-5.

11 Hedges T R, Gieger G L, Albert D M. The clinical value of negative temporal artery biopsy specimens. Arch Ophthalmol 1983; 101: 1251-4.

12 Ellis M E, Ralston W S. The ESR in the diagnosis and management of the polymyalgia rheumatica/giant cell arteritis syndrome. Ann Rheum Dis 1983; 42: 168-70.

13 Sinning M A, Wood W G, Huston K A, Davidson K C, Pikerton J A. Giant cell arteritis with peripheral vascular compromise. Mo Med 1983; 80: 189-93.
14 Klein R G, Hunder G G, Stanson A W, Sheps S G. Large artery involvement in giant cell (temporal) arteritis. Ann Intern Med 1975; 83: 806-12.

15 Hall S, Lie J T, Kurland L T, Persellin S, O'Brien P C, Hunder C G. The therapeutic impact of temporal artery biopsy. Lancet 1983; ii: $1217-20$.

16 Goodman B W Jr. Temporal arteritis. Am J Med 1979; 67: 839-52.

17 Elliot P D, Baker H L, Brown A L. The superficial temporal angiogram. Radiology 1972; 102: 635-7.

18 Barrier J, Potel G, Renaut-Hovasse $H$, et al. The use of Doppler flow studies in the diagnosis of giant cell arteritis. JAMA 1982; 248: 2158-9.

19 Bengtsson B A, Malmvall B E. Giant cell arteritis. Acta Med Scand 1982; 658 (suppl): 1-102.

20 Morgan G J, Harris E D. Non giant cell temporal arteritis. Arthritis Rheum 1978; 21: 362-6.

21 Healey L A, Wilske K R. Presentation of occult giant cell arteritis. Arthritis Rheum 1980; 23: 641-3.

22 Ludmerer $\mathrm{K} \mathrm{M}$, Kissane $\mathrm{J}$ M. Fever of unknown origin in a 71-year-old woman. Am J Med 1985; 79: 373-84.

23 Calamia K T, Hunder C G. Giant cell arteritis (temporal arteritis) presenting as fever of undetermined origin. Arthritis Rheum 1981; 24: 1414-8.

24 Fauchald $P$, Rygold $O$, Oystese B. Temporal arteritis and polymyalgia rheumatica. Clinical and biopsy findings. Ann Intern Med 1972; 77: 845-52.

25 Strachan R W. How J. Bewsher P P. Masked giant cell arteritis. Lancet 1980; i: 194-6.

26 Ayoub W T, Franklin G M, Torretti D. Polymyalgia rheumatica. Duration of therapy and long-term outcome. Am J Med 1985; 79: 309-15. 